\title{
EL ESTUDIO DE LOS ADVERBIOS ESPAÑOLES EN LOS LUSOHABLANTES QUE APRENDEN ESPAÑOL
}

\author{
J. Agustín TORIjANO \\ Universidad de Salamanca
}

\begin{abstract}
RESUMEN
El presente artículo aborda el estudio de los adverbios españoles en la interlengua escrita de estudiantes de español cuya lengua nativa es el portugués. El objetivo general del estudio es analizar, clasificar y describir los errores según el «criterio de recurrencia» o «frecuencia» en un vasto grupo de estudiantes lusófonos. La finalidad será determinar cuáles son las zonas de mayor dificultad en el aprendizaje de los adverbios españoles, de manera que los resultados de dicho estudio puedan establecer las características de su proceso de enseñanza/aprendizaje y de lo que el autor denomina la «interlengua colectiva». Los objetivos específicos son: a) aumentar nuestro conocimiento acerca de la interlengua referida a los adverbios de estos estudiantes, como grupo representativo de los hablantes de su lengua; b) describir e intentar explicar las causas de las producciones erróneas; c) considerar las posibles actuaciones didácticas sobre el problema.
\end{abstract}

Palabras clave: adverbios, lingüística aplicada, portugués, interlengua.

\section{ABSTRACT}

This paper focuses on the study of Spanish adverbs in the written interlanguage used by Portuguese native-speakers studying Spanish. Its general aim is error analysis, classification and description, according to the «recurrence or frequency criterion» in a large group of Portuguese-speaking students. Its purpose is to determine which are the areas of greater difficulty in learning Spanish adverbs, with a view to establish the characteristics of its teaching/learning process and what the author calls "collective interlanguage». The specific aims are: a) to improve our knowledge about the interlanguage as represented by the adverbs used by these students, considered as a representative group of Portuguese speakers; b) describing and attempting at an explanation of the causes of the errors; c) considering possible teaching actions to resolve the problems.

Key Words: Adverbs, Applied Linguistics, Portuguese, «interlanguage».

\section{INTRODUCGIÓN}

El presente estudio sobre el adverbio español y su aprendizaje pretende ser un intento de aplicación práctica de los principios teóricos y 
metodológicos de los paradigmas de investigación del aprendizaje de segundas lenguas -Análisis Contrastivo (AC), Análisis de Errores (AE) e Interlengua (IL)-, realizados sobre la producción escrita (PE) de estudiantes de español cuya lengua nativa es el portugués, en las variedades europea y americana ${ }^{1}$.

El objetivo es analizar, clasificar y describir los errores más frecuentes, es decir, seguir fundamentalmente un «criterio de recurrencia» o de «frecuencia» en un amplio grupo de estudiantes ${ }^{2}$ que comparten la condición de tener el portugués como Lengua Materna (LM). La finalidad será determinar cuáles son las zonas de mayor dificultad en el aprendizaje de los adverbios españoles, de manera que los resultados de dicho estudio nos ofrezcan los indicios de cómo es la interlengua (Durão 1997 y 2007), lo que llamamos la «interlengua colectiva"3, de estos estudiantes en lo referente a esa parte de la oración.

Los objetivos fundamentales que nos proponemos alcanzar son:

a) conocer más acerca de la interlengua referida a los adverbios de estos estudiantes, como grupo representativo de los hablantes de su lengua;

b) describir e intentar explicar las causas de las producciones erróneas;

c) reflexionar y actuar sobre el problema.

El esquema básico será muy sencillo, pero no necesariamente simple, para lo cual nos atendremos a una triple medida que pretende cuantificar y calificar el estado de la cuestión de manera satisfactoria. Dicha medida se basa en los problemas generales producidos por:

1. la «omisión» de elementos necesarios,

2. la «adición» de partes innecesarias y

3. la «elección errónea y problemas afines».

Somos conscientes de la amplitud del tercer epígrafe -interesada actualización ad hoc del modelo propuesto por G. Vázquez para su Criterio Descriptivo (1986), después Lingüístico (1991 y 1999)-, pero lo establecemos de este modo convencidos de que todos los elementos de

\footnotetext{
${ }^{1}$ A modo de comparación complementaria, haremos referencias al comportamiento que algunos fenómenos estudiados presentan en una lengua que, como el inglés, mantiene con el español y con el portugués una mayor distancia interlingüística. Igualmente, y por tratarse de una lengua no romance, puede presentar errores de utilidad en comparaciones que podríamos llamar «triangulares», sin olvidar la peculiaridad del inglés como línea vehicular. Para ello, hemos realizado calas de selección y análisis sobre la PE de estudiantes cuya lengua nativa es el inglés, principalmente norteamericanos, y, en menor medida, británicos.

${ }^{2}$ La cifra de las Producciones Escritas analizada se estableció en torno a las 2.750 redacciones del Diploma de Español como Lengua Extranjera, en su nivel denominado básico: DBE.

3 Torijano 2003, passim.
} 
una lengua no presentan las mismas características para que deban ser rasados de forma indiscriminada, por lo que tales «problemas afines» se concretarán según sus características propias.

De manera oportuna profundizaremos en aquellos problemas específicos de las dos lenguas en liza, de manera que sea más diáfano el contraste entre ambas. Como queda dicho, el análisis se establece sobre las PE de 2.750 los candidatos de habla portuguesa, de ambos lados del Atlántico, especialmente de Brasil, por lo que siempre que no se indique lo contrario, debe entenderse que hablamos del portugués, con puntuales menciones al inglés o a otras lenguas que sirvan de comparación y contraste.

Por lo que se refiere a las características del adverbio, digamos que, contra lo que podría pensarse a priori, esta parte de la oración es una de las que más diferencias presenta entre ambas lenguas en las consideraciones gramaticales teóricas, dado que las clasificaciones y conceptos no sólo no siempre coinciden sino que a veces son opuestos. Debe añadirse a esto la -a veces desasosegante para muchos- existencia de otra fisura en la unidad lingüística del portugués en sus dos realizaciones, cisatlántica y transatlántica, cuyos fundamentos teóricos en este asunto tampoco concuerdan. No hay, pues, consonancia teórica entre las gramáticas española y luso-brasileña para establecer una clasificación y, por tanto, un concepto único de adverbio.

\section{Problemas terminológicos}

Las diferencias de consideración se ponen de manifiesto en el hecho de que las clasificaciones de la gramática española no se corresponden con las portuguesas ni con las brasileñas, ni aun éstas dos entre sí, en la idea de qué debe considerarse adverbio y qué no.

Por un lado, la gramática española establece una clasificación (a) semántica y otra (b) formal o más exactamente sintáctica:

a) la primera, más tradicional, se basa en criterios de significado y establece las clases siguientes: adverbios de lugar; de tiempo; de modo; de afirmación; de negación; de cantidad; de deseo; de duda, posibilidad o probabilidad; de exclusión, inclusión o adición; de identidad; de exclamación; y otros ${ }^{4}$, a las que deben añadirse las formaciones de dos o más palabras, las locuciones adverbiales, clasificables en la misma taxonomía semántica que los adverbios propios.

\footnotetext{
${ }^{4}$ Creemos innecesario enumerar la lista de los adverbios que pertenecen a cada clase, si bien llamamos la atención sobre la dificultad de etiquetar partículas como consecuentemente, contrariamente, justamente, justo, siquiera o viceversa.
} 
b) la segunda incluye los adverbios «relativos» (donde, cuando, cuanto y como) y los interrogativos-exclamativos (dónde, cuándo, cuánto y cómo)-considerados por algunos gramáticos como meras variantes de los anteriores-, que aparecen en las oraciones interrogativas tanto directas como indirectas, y que añaden estos valores a los que les son propios.

Por otro lado, las gramáticas portuguesa y brasileña, como queda de manifiesto en tantas monografías descriptivas y normativas, desde la tradicional de Vázquez Cuesta 1987 hasta las más actuales, lejos de coincidir con la española, divergen de ella y entre ellas mismas, lo cual produce un panorama realmente desconcertante para quienes mantienen la proximidad de ambos idiomas como garantía de facilidad de su estudio, problema tratado ampliamente en su día de forma más genérica pero determinante por Lado 1957 [1991] o Weinrich 1974, entre otros muchos.

No se trata de hallar diferencias inexistentes entre el concepto de «adverbio» y el de «advérbio», sino que hablamos de discordancias clasificatorias que más afectan al análisis morfosintáctico que a la comunicación.

Tales discrepancias abarcan tendencias radicales que llegan a proponer la eliminación de la denominación de «adverbio», como hace B. Pottier $1964^{5}$, o la disensión existente entre las modalidades americana y europea del portugués, o, sin ser tan extremo, a diferenciar taxonomías separadas para ambas modalidades de esta lengua:

Así, para la Nomenclatura Gramatical Brasileira debe hablarse de los siguientes tipos:

\begin{tabular}{|l|l|}
\hline 1. A. de afirmação 'afirmación': & $\begin{array}{l}\text { sim, certamente, efectivamente, realmente, } \\
\text { pois não, pois sim, deveras, etc.; }\end{array}$ \\
\hline 2. A. de dúvida 'duda': & $\begin{array}{l}\text { acaso, porventura, possivelmente, prova- } \\
\text { velmente, quiçá, talvez, etc.; }\end{array}$ \\
\hline 3. A. de intensidade 'cantidad': & $\begin{array}{l}\text { assaz, bastante, bem, demais, mais, menos, } \\
\text { miuto, pouco, quanto, quão, quase, tanto, } \\
\text { tão, etc.; }\end{array}$ \\
\hline 4. A. de lugar: & $\begin{array}{l}\text { abaixo, acima, adiante, aí, além, ali, aco- } \\
\text { lá, algures, alhures, aquém } \\
\text { através, aqui, atrás, defronte, dentro, detrás, fora, } \\
\text { junto, lá, longe, onde, perto, etc.; }\end{array}$ \\
\hline
\end{tabular}

${ }^{5}$ Citado por C. Cunha y L. Cintra 1991.

${ }^{6}$ Tanto algures 'en algún lugar' como alhures 'en otro lugar' no tienen correlato sintético en español actual. A medio camino se encontrarían além, aquém y acolá, 'allende' y 'acullá', respectivamente, existentes en español pero de restringido uso, aunque no así en portugués. 


\begin{tabular}{|c|c|}
\hline 5. A. de modo: & $\begin{array}{l}\text { assim, bem, debalde, depressa, devagar, mal, } \\
\text { melhor, pior, etc., y casi todos los termi- } \\
\text { nados en -mente. }\end{array}$ \\
\hline 6. A. de negação 'negación': & não, nunca, nada, jamais, tampouco, etc. \\
\hline 7. A. de tempo 'tiempo': & $\begin{array}{l}\text { agora; ainda, amanhã, anteontem, antes, } \\
\text { breve, cedo, depois, então, hoje, já, jamais, } \\
\text { logo, nunca, ontem, outrora, sempre tarde, } \\
\text { etc. }\end{array}$ \\
\hline
\end{tabular}

Por muy diferentes motivos, la Nomenclatura Gramatical Portuguesa establece que deben añadirse otras tres clases:

1. A. de ordem 'orden': primeiramente, ultimamente, depois, etc.;

2. A. de exclusão 'exclusión' y

3. A. de designação 'designación'.

Los dos últimos han sido incluidos por la Nomenclatura Gramatical Brasileira en un grupo aparte, por considerar que no presentan las características ya vistas de los adverbios, y que a veces reciben el poco significativo e inexacto nombre de "palabras denotativas».

A este grupo pertenecerían, según los gramáticos brasileños, palabras que denotan:

\begin{tabular}{|l|l|}
\hline 1. inclusão 'inclusión': & até 'hasta', inclusive, mesmo, também, etc.; \\
\hline 2. exclusão 'exclusión': & $\begin{array}{l}\text { apenas, exceto, menos, salvo, senão, só, so- } \\
\text { mente, etc.; }\end{array}$ \\
\hline 3. designação 'designación': & eis 'he aquí'; \\
\hline 4. realce: & cá, lá, é que, nãa, só, etc.; \\
\hline 5. rectificação 'rectificació': & aliás, ou antes, ou melhor, ou seja, etc.; \\
\hline 6. situação 'situación': & afinal, agora, então, mas, etc. \\
\hline 7. explicação 'explicación' & a saber, isto é, ou seja, por exemplo, etc. \\
\hline
\end{tabular}

7 Según esto, serían ejemplos de palabras denotativas las subrayadas en estas secuencias:

- Não vou, não: palabra de realce.

- Eu até posso ajudá-la, se você não insistir tanto!: palabra de inclusão.

- Queríamos salvar a situação, isto é, ajudar a salvar: palabra de explicação. 
Por su parte, para la gramática portuguesa los dos primeros tipos son propiamente adverbios, mientras que denomina advérbios de oração, las consideradas palavras denotativas de situação en Brasil.

En relación con los «adverbios relativos» y los «interrogativos-exclamativos», las dos gramáticas lusófonas también se separan hasta puntos extremos.

No obstante, y frente a las virtuales dificultades que esto podría plantear, las diferencias en las tipologías constituyen una casuística meramente especulativa y teórica, toda vez que el hablante de la otra lengua no necesita hacer distingos entre si lo que quiere usar pertenece a una clase o a otra. Cuestión aparte es la eventualidad de realizar un análisis morfosintáctico de la oración, niveles de profundización sólo aplicables en procesos de perfeccionamiento o de necesidades específicas.

Como es habitual, para el aspirante a usuario de la lengua es más trascendental saber que ainda, además de 'todavía', presenta valores como «incluso», «además», o «aunque», y que su combinación con que no siempre tiene los mismos significados que en portugués. Cuando esto no ocurre, toda especulación taxonómica cede ante secuencias como:

(1) *y visitaremos lugares $[\ldots]$ que tu aunque no conoces.

Lo que es una evidente transferencia negativa (Andersen 1983) del valor temporal de ainda, 'todavía', con la conjunción adversativa.

\section{ADVERBIOS Y LOCUCIONES ADVERBIALES}

A pesar de todo lo visto sobre la distribución interna del adverbio en cada sistema lingüístico, la naturaleza de esta clase de palabras es idéntica en ambas lenguas, lo que significa que comparten su función, no sólo la etimológica de «cerca o próxima al verbo», sino también la de adjunto a un adjetivo o a otro adverbio, así como la capacidad de extender su influencia sobre un grupo de palabras cuyo núcleo sea igualmente un verbo, un adjetivo, un adverbio o cualquier otra palabra o grupo de palabras que funcione del mismo modo.

Es también común a ambas lenguas su invariabilidad en lo que se refiere al género y al número, aunque también las dos comparten la posibilidad de admitir morfemas como sufijos aumentativos o diminutivos, con valor connotativo:

agora 'ahora' - agorinha 'ahorita';

cedo 'pronto' - cedinho 'prontito';

devagar 'despacio' - devagarinho 'despacito';

perto 'cerca' - pertinho 'cerquita'; etc. 
Asimismo, es común a ambos sistemas la existencia de los grados comparativo y superlativo.

En cuanto a las locuciones adverbiales, estas uniones de dos o más palabras -generalmente una preposición más sustantivo, un adjetivo o un adverbio- desempeñan la misma función que éste último. Esto sucede de la misma forma en los dos idiomas, aunque también sus diferencias son análogas, especialmente en lo que afecta a las consideraciones teóricas, y no tanto a los usos o valores.

\subsection{Características morfológicas y ortográficas}

Presentamos algunas de las formas más habituales de adverbios y locuciones adverbiales en portugués, a fin de poder establecer mejor el análisis contrastivo, y conocer qué causa el error en los aprendices.

Por regla general, sin considerar ciertas particularidades ortográficas, es muy común que la diferencia morfológica entre las formas españolas y las portuguesas radique en la presentación en una o en dos palabras, lo cual no sólo afecta a la cuestión gráfica sino también a su clasificación, es decir, pueden ser adverbios o locuciones, según aparezcan en una o dos palabras.

El conocimiento de las formas debería ser tal que no sólo evitara la presencia de errores formales en las producciones de los alumnos, sino que además no confundiera a los profesores a la hora de atribuir tales desviaciones a razones de ortografía, especialmente cuando los estudiantes escriben adverbios en una sola palabra cuando en español son dos, y viceversa.

Para ello, y como ocurre con otras categorías, estimamos que una mínima observación al modelo de partida del estudiante, a su LM, ofrece la información precisa para analizar debidamente las causas de dichos problemas gráficos.

A modo de ejemplo, citemos algunos casos significativos:

debalde, decerto, defronte, deveras, em cima, enquanto o talvez

Se constata, pues, una tendencia a la aglutinación, de características idénticas a las que presenta la propia evolución interna del español, que nos sirve de modelo.

Son todavía recientes realizaciones de esa tendencia que de prisa haya pasado a ser deprisa, que en seguida parezca ceder ante enseguida, y que se prefiera enfrente a en frente. Pero más atrás en el tiempo, podríamos remontarnos a estadios pasados en los que se formaron, por la misma vía de aglutinación, otros adverbios como entretanto, así, dentro, desde, encima (portugués em cima), debajo, o mucho antes antaño, ahora, o adrede, 
tanto si se acepta la etimología ad directum, a través del catalán adret, como si se considera la propuesta del gótico at *ret.

Por lo que hace a las locuciones adverbiales en portugués, y siguiendo un criterio semántico, pueden clasificarse de la siguiente manera:

\begin{tabular}{|c|c|}
\hline $\begin{array}{l}\text { 1. Afirmação 'afirmación' } \\
\text { (o Dúvida) 'duda': }\end{array}$ & $\begin{array}{l}\text { com certeça }{ }^{8} \text {, por certo, sem dúvida, pois } \\
\text { não, etc.; }\end{array}$ \\
\hline 2. Intensidade 'intensidad': & de muito, de pouco, de todo, etc.; \\
\hline 3. Lugar: & $\begin{array}{l}\text { à direita, à esquerda, à distância, ao lado, } \\
\text { de dentro, de cima, de longe, de perto, em } \\
\text { cima, para dentro, para onde, por ali, por } \\
\text { aqui, por dentro, por fora, por onde, por per- } \\
\text { to, etc.; }\end{array}$ \\
\hline 4. Modo: & $\begin{array}{l}\text { à toa, à vontade, de má vontade, ao con- } \\
\text { trário, ao léu, ao todo, às avessas, às cegas, } \\
\text { às claras, às escuras, às apalpadelas, às di- } \\
\text { reitas, às pressas, às vezes, com gosto, de cor, } \\
\text { de regra, debalde, deveras, em geral, em si- } \\
\text { lêncio, em vão, gota a gota, passo a passo, } \\
\text { por acaso, etc.; }\end{array}$ \\
\hline 5. Negação 'negación': & de forma alguma, de modo nenhum, etc.; \\
\hline 6. Tempo 'tiempo': & $\begin{array}{l}\text { à noite, à tarde, à tardinha, de dia, de } \\
\text { manhã, de noite, de quando em quando, de } \\
\text { vez em quando, de tempos em (a) tempos, em } \\
\text { breve, pela manhãa, etc. }\end{array}$ \\
\hline
\end{tabular}

\subsection{Errores generalizados}

En general, las gramáticas de las lenguas románicas consideran que el adverbio funciona como elemento de rango sintáctico terciario, lo cual no debería traducirse en falta de atención en la lingüística aplicada ni, por tanto, en la enseñanza de una L2.

Las diferencias morfológicas que hemos visto no son, sin embargo, las únicas, dado que adverbios y locuciones son depositarios de una significativa cantidad de falsos amigos. No son escasas las divergencias se-

${ }^{8}$ De la misma forma que ocurre en español con quizá, tal vez, etc., la posición de esta locución puede transmitir la idea de «duda»:

Com certeza o Congresso não aprovará o projeto,

o, por el contrario, mayor o absoluta «seguridad»:

O Congresso não aprovará o projeto, com certeza. 
mánticas existentes en las voces adverbiales de ambas lenguas, lo cual es causa de ruido comunicativo cuando no de fracaso en la comunicación.

Ante tales diferencias, entre los adverbios y las locuciones de ambas lenguas, no parece ilógico hallar secuencias erróneas debidas a interferencias de la LM, bien en un estado primitivo (1), por las que el aprendiz traspone literalmente la forma y el significado de la voz supuestamente análoga en su idioma, bien combinada con los efectos de cierta «intraferencia», en una fase ligeramente más avanzada (2) aunque no lo suficiente como para evitar el error, generalmente por una equivocada suposición de igualdad. Estas últimas constituyen los llamados «casos frontera», aplicables también a estudios sobre el léxico de ambos idiomas.

Estas tomas del corpus ratifican los fenómenos descritos:

(2) *venir novamente al Brasil; * onde la naturaleza muere para siempre; *onde la corrupción es la unica ley; *de unos tiempos para cá; *olvidarte de tu amiga cá en San Pablo; *Brasil tiene ainda la floresta amazónica; *antes que sea tarde demais; *yo lá [allí] estaré desde el día diez; *talvez acaben este mes; * quando la industria llega, los animales se van; *Sucede que quando los veo están borrachos y ponen la culpa en el vino; * no sé quándo pero si dónde: aquí; * Me encanta viajar, especialmente quando puedo conocer personas; *afinal [port. afinal, 'por fin, finalmente'] podremos comer juntos; *afinal sé que podré entrar; *quedo ay [ahí] siempre que voy a Madrid; *una empresa de ay; *voy a trabajar ay el año que viene; * lá viveron toda su vida; *Non voy a decir que non me gusta; *las cosas non han cambiado mucho; voy somente [sólo] dar una vuelta; ${ }^{*}$ so estoy aguardando; ${ }^{*}$ Me encanta ir as clases quase todos los días; *no entanto [port. no entanto, 'mientras, mientras tanto'], destruyen la naturaleza sin freno; etc.

(3) *ay entoas [port. aí então] el petróleo es la causa unica; *Lo has obtenido mismo con tu sangre; *También puedo estar viviendo en Italia o mismo en São Paulo; * tiene problemas pero mismo así me encanta; * mismo así no dejó de salir; *No pueden pagar transportes mismo que la escuela sea pública; *hasta mismo nuestros ambientes; *de ahora adelante; *dentre poco; *ella estuvo acerca de mí; *hasta breve [port. até breve, 'hasta pronto'], mi amigo; *es como matarse a los pocos [port. aos poucos, 'poco a poco']; ${ }^{*} ¿$ Mi bebida favorita? Cualquiera, yo soy mismo una esponja para los líquidos; etc.

\subsection{Errores específicos}

La abrumadora presencia en las producciones, y por tanto en los corpus, de ciertos casos muy específicos de errores concitan especial interés por su tendencia a la fosilización y a su dificultad para ser erradicados de la interlengua, por lo que dedicamos un análisis pormenorizado a cada uno de ellos. 
1. Son dignos de especial mención los errores producidos por las formas muy/mucho. Como es sabido, la forma del adjetivo en español es mucho/- $a /-o s /-a$, pero es también la forma (invariable, lógicamente) que adopta muy cuando el adverbio modifica a un comparativo (mucho más alta, mucho peores). Esta diferenciación es inexistente en portugués, donde se produce una neutralización en la forma muito para todos los casos

(4) a. A minha morada está muito longe.

b. Tenho comido muito arroz.

c. O macho deste peixe é muito mais pequeno do que a fêmea.

Se trata de un error muy susceptible de fosilización, y con fuerte presencia incluso en hablantes de niveles avanzados. La confusión se aprecia en secuencias como éstas:

(5) *porque la esperaba por muy tiempo; * una novia muy guapa y que me hiz muy bien; * estamos con muy saludad; *le deseo muy éxito en su nuevo puesto; *todo va muchísimo bien; * eso es una cosa mucho peligrosa; *Muchas pocas personas tienen conciencia; *Ellas viven mucho lejas; etc.

Incluso en frases como: *ahora podrá tener un coche muy mejor o *vamos tener una casa muy mayor, etc., en las que se observa la confusión formal, pero no de la función adverbio/adjetivo. En ambas frases, la forma correcta debería ser mucho, pero también con función adverbial.

Este conflicto formal (o, en su caso, funcional) entre adverbio y adjetivo vuelve a repetirse con la falsa flexión del primero, como se observa también en

(6) a. *Las poblaciones más lejas no lo conocían

b. *espero que tus éxitos no seán despacios; etc.

o exactamente con el fenómeno contrario, la adverbialización del adjetivo:

(7) *en un futuro no tan lejo.

2. El adverbio mais/más protagoniza un error demasiadas veces repetido, lo cual parece revelar nuevamente un problema muy enraizado en el PEA de ELE de los lusófonos. Nos referimos a los problemas de orden, especialmente en las oraciones negativas con valor temporal, en las que mais, colocado siempre detrás del verbo, es quien transmite dicho valor, como ocurre en otras lenguas ${ }^{9}$. plus.

${ }^{9}$ Inglés: She doesn't work anymore; italiano: Lei non lavora di piú; francés: Elle ne travaille 
Esta construcción, profundamente arraigada en portugués, es criticada por los gramáticos más puristas, de forma que en lugar de la común

(8) Ela não trabalha mais.

proponen

(9) Ela ja não trabalha.

Pese a ello, la evidencia de su vitalidad en portugués se pone de manifiesto ante la abundancia en el corpus de ejemplos como los siguientes:

(10) * *uando la recibí me puse a reír y no parava más; *Cuando vio que no acordaba más llamó a la policia; * el hombre [...] no está más progresando; *no funciona más; *no podemos mas continuar a destruir la vida; * no podemos más olvidarnos; * no quería más quedarse allí; *no van mas aprobar proyectos; *hoy no es más amiga de Luis; etc.

Asimismo, y sin necesidad de ser una oración con valor temporal, mais mantiene su posición posverbal, alteración sintáctica que se deja traslucir en su realización en una L2, en evidente señal de interferencia.

(11) *Diego iba a hacer más una vez una travesura; * [te digo] mas una vez muchas felicidades; * no tengo más ninguna palabra; * quiero más una vez invitarte; *su padre no tendría más ninguna oportunidad; *No pude verla mas ningún otro dia; etc.

Aunque parece clara la filiación del error, no debe descartarse la posibilidad de interferencias del modelo meridional del español, y más concretamente en ciertas zonas del andaluz, en las que no es difícil detectar, en el habla cotidiana, frases como

(12) a. No vuelvo más nunca a Sevilla.

b. No tengo más nada que decir.

3. Las diferencias semánticas entre el portugués logo y el español luego son igualmente visibles en la gran cantidad de producciones erróneas que la interferencia causa en los estudiantes.

Es este un caso en el que la ortodoxia oficial entra en conflicto con la norma general. Oficialmente, en español, el adverbio luego significa, -según el DRAE, que continúa colocándola como primera acepción«prontamente, sin dilación», antepuesto al uso estándar, que ha generalizado el valor de «después, más tarde», frente al portugués logo, que conserva el valor de «tiempo inmediato», con lo que estamos ante un error, al menos a oídos de los hablantes nativos. 
Cabe decir que este valor de proximidad, presente en español medieval y clásico, puede encontrarse aún en zonas dialectales del gallego y del antiguo dominio leonés ${ }^{10}$, sin olvidar algunos restos en el español estándar como la expresión ¡hasta luego!, más próxima a ¡hasta ahora! o ¡hasta pronto!, que un supuesto ¡hasta después!, sólo utilizado cuando se tiene cierta seguridad de un encuentro real.

Aunque la diferencia a veces es casi imperceptible, como vemos en

(13) *escribame [tú] luego; *luego vamos nos tener; * que vengas a mi casa luego; etc.

En otras ocasiones la pérdida del valor original produce que el oyente hispanohablante no comprenda lo que su interlocutor quiere transmitirle -pese a que crea estar haciéndolo- fenómeno que dificulta o imposibilita el acto de habla:

(14) *mis próximas vacaciones están por venir luego; *mi deseo es verte logo que pueda; *empezó con mucha energia pero se canso luego; etc.

4. Es asimismo significativa la potencialidad de causar errores de la partícula ainda, una de las más polisémicas del portugués, lo cual se torna problemático al compartir solamente algunos valores con el español, bien en una relación palabra-palabra, bien palabra-locución o palabra-perífrasis.

Su valor primero es equivalente al español «todavía, aún», significado que no suele plantear demasiados problemas. Sin embargo, conviven con éste otros usos que presentan un abanico demasiado amplio como para que el hablante no bilingüe se vea libre del error a la hora de elegir el correcto:

algún día (futuro; de nuevo, nuevamente; además, así como; por fin, finalmente; nunca (pasado); no obstante; al menos, por lo menos (condicionales); (ni) siquiera; incluso, hasta; etc.

Además, y en combinación con que, adquiere el valor de «aunque, a pesar de que», hecho con visibles consecuencias para el aprendizaje del español, dado que es muy habitual la identificación de ainda (que) con aun(+)que. Es uno de los elementos más problemáticos en el proceso didáctico-docente, porque llega a convertirse en un obstáculo para el avance en el proceso de la interlengua. A modo de muestra, sirvan

\footnotetext{
10 Todavía hoy es posible oír a los padres, y más frecuentemente a las madres, decirles a sus hijos cuando éstos se disponen a salir por la noche: "¡Ven luego, que sabes que no me duermo hasta que no vienes!".
} 
estas secuencias que ilustran la múltiple confusión, -mezclando valores con formas de ambos idiomas-, generada por ainda:

(15) *aún ['aunque'] estea [port. esteja, 'esté'] jubilada, siempre hace muchas cosas; *aunque [aún] ahora lloraba mucho de las cosas que le dijera hace tres años; ${ }^{*}$ iqué placer recibir tu carta aunque traiga buenas noticias!; *Su preocupación es [...] aunque pequeña, pero será mayor; *y visitaremos lugares $[\ldots]$ que tu aunque no conoces; *ni que [aunque] fuera por unos días; *son cosas lógicas, hasta que obvias; etc.

5. Los adverbios bem/mal cuando aparecen modificando a determinados verbos copulativos o semicopulativos (estar, ficar, continuar, parecer, etc.) pueden alternar con sus adjetivos correspondientes $\mathrm{bom} / \mathrm{mau}$, con leves matices de significado.

Esto también puede observarse en las exclamaciones (Está muito bom! = Está muito bem!), caso análogo al que sucede en el español de América, donde no es extraño oír:

(16) ¿Qué bueno que viniste!

cuando un español esperaría:

(17) ¿Qué bien que viniste/has venido/hayas venido!

Debe tenerse también presente en el análisis de errores una característica propia de las expresiones mais bem/mais mal, dado que en portugués se consideran correctas si aparecen seguidas de participio, y se usan en lugar de las formas sintéticas correspondientes melhor y pior:

(18) Aquele deputado foi o mais bem preparado secretário de Estado que já tivemos.

Por el contrario, si aparecen colocadas detrás del participio, deben usarse melhor o pior:

(19) Desconheço casa construida melhor que essa.

6. Merece destacarse la paradoja semántica que produce la locución adverbial afirmativa pois não, utilizada como respuesta positiva de asentimiento a preguntas o sugerencias. Frente a lo que un hispanohablante podría deducir por la grafía, la locución se usa con valor afirmativo.

(20) -O senhor polícia poderia indicar-me onde é que estamos? -Pois não! Agora nós estamos no largo do Chiado. 
La contextualización permite, en este caso, descubrir después de una primera vacilación, el verdadero significado de la expresión ${ }^{11}$.

Como complicación añadida al PEA, el español tampoco es ajeno a este tipo de aparentes paradojas, que no son sino restos de oraciones de valor absoluto y de respuesta taxativa que han ido quedando reducidas a la parte más enfática o con mayor carga fónica.

Piénsese en el efecto producido en los estudiantes de español L2 ante respuestas del tipo ;cómo no!, en la que la partícula negativa no parecería dejar lugar a dudas. A este respecto, debe compararse esta expresión con otras del tipo ni que lo digas (con la variante coloquial y que lo digas), o en absoluto, de valor negativo frente a lo que parecen indicar los significantes.

Más difíciles de identificar son dos expresiones aparentemente iguales, que, sin embargo, representan un problema de reconocimiento y sobre todo de uso. Nos referimos a (a) toda mi ( $t u$, su, etc.) vida frente a (b) en (toda) mi ( $t u$, su, etc.) vida. Un rápido análisis nos permite diferenciar el valor positivo de la primera, equivalente a «siempre», en oposición al de la segunda, precisamente análogo a «nunca»:

(20) a. Toda mi vida he viajado en tren.

b. En mi vida he viajado en tren.

La situación no facilita la tarea, toda vez que los elementos de juicio de un aprendiz no son todavía válidos para entender el cambio de polaridad de (b), debido a la presencia de palabras aparentemente similares a las de (a), o a la ausencia de partículas negativas, hasta el punto de que la interiorización del sentido negativo plantea dudas en el concepto y mecanismo de la negación en español.

7. Por último, reseñamos más brevemente algunos de los adverbios y locuciones que por su forma inducen a significados erróneos, acompañados por su valor en portugués:

- a horas: 'a tiempo';

- a olhos vistos: 'a ojos vistas';

- antes: 'anteriormente'; 'antes bien, mejor dicho, más bien', etc.;

- apenas: 'sólo', 'únicamente'12,

- enquanto: 'mientras'

11 Sucede lo mismo con oraciones del tipo

Você não tem uma boa impressão dos portugueses, pois não?

Tú no tienes una buen impresión de los portugueses, ¿̇verdad?

${ }^{12}$ La traducción correcta del significado español de apenas sería mal, quase não, etc. El valor de apenas en español es el de «casi no», excepto que vaya seguido de una expresión de cantidad, circunstancia en la que coincide con el portugués: «solamente». 
- de novo: 'recientemente';

- de revés: 'de soslayo, oblicuamente, indirectamente';

- de uma vez (por uma vez): 'al momento'; 'una vez' ( $\neq$ de vez);

- desde logo (ver logo, supra): 'enseguida, inmediatamente'; 'para empezar', etc.

- mesmo: (como adverbio) 'realmente' / 'incluso', 'hasta', (= francés même), etc.

- naquela altura: 'en aquel momento';

- por acaso: 'fortuitamente', 'la verdad es que', 'realmente', etc.

- por certo: 'ciertamente' ( $\neq$ a propósito, por falar em, por sinal);

- por ora: 'por el momento', 'por ahora'; etc.

- sempre: 'finalmente', 'por fin', 'en todo momento'; 'de cualquier modo', etc.

- tão-pouco: 'ni siquiera' ( $\neq$ também não);

- já: 'ahora' (Até já!; desde já, ‘'hasta ahora!'; 'desde ahora’); 'nunca antes'.

De forma que oraciones como

(21) a. As condições são as piores que já vi

b. Já ouvi frase formulada pior que a sua,

deben traducirse, respectivamente, por

(22) a. Las condiciones son las peores que he visto (nunca, en mi vida, etc.)

b. Nunca (en mi vida) he oído una frase peor construida que la suya $^{13}$.

Por el contrario, já nunca debe usarse como respuesta afirmativa de asentimiento $(y a)$.

\section{AdVERBIOS RELATIVOS}

Se produce un nuevo desacuerdo entre ambos idiomas en la consideración de este tipo de adverbios. Mientras en español ocupan esta clasificación donde, cuando, cuanto y como, que desempeñan las funciones de complementos circunstanciales y, lógicamente, de nexos introductores de oraciones de relativo, en portugués (y únicamente en la gramática portuguesa y no en la brasileña) sólo se admite la existencia virtual de onde como adverbio relativo por desempeñar la función de adjunto adverbial (en lugar en el que).

${ }^{13}$ Es frecuente, por tanto, encontrar entre las producciones de los candidatos de niveles superiores secuencias del tipo:

* ¿Como puedo enfadarme con el hombre simpatico que ya conocí en mi vida? 


\subsection{Errores generalizados}

Si existe un error esperable, a tenor de la descripción de la LM del hablante lusófono, podría ser el que se deriva de la ausencia del concepto de adverbio relativo, hecho que determina de forma incontestable la existencia de secuencias caracterizadas por la ausencia de este tipo de adverbios.

Las secuencias con desviaciones de la norma parecen revelar, salvo escasas excepciones (*en las ciudades onde vive el hombre), evidente falta de esta estructura en la LM, si bien, como en otras ocasiones, no debe eliminarse la posibilidad de cierta influencia del español americano, donde la reducción de los relativos a que es muy frecuente, así como la eventualidad de intervención de otros idiomas, como puede ser el inglés, el francés y hasta el italiano, en los que es correcta esa misma reducción a que.

Secuencias como las siguientes ilustran este tipo de error:

(23) *es con alegría que contesto a tu última carta; * fue con mucha alegría que ayer recebí tu carta; * era por medio de medio de esta varanda que separaba; *haciendo los trámites fue que me di cuenta; *fue entonces que descubriste todo; *Fue en esa casa que nos vimos la primera vez.; etc.

\section{AdVERBIOS INTERROGATIVOS-EXCLAMATIVOS}

Dedicamos un apartado específico a esta clase de palabras, pertenecientes a las llamadas palabras-cu ${ }^{14}$, clase formada por los pronombres y adverbios relativos, interrogativos y exclamativos (más concretamente a las denominadas exclamativas-cu, a las que pertenecen las unidades qué, cuál, cómo y cuánto), con las que se puede efectuar la función ponderativa de cuantificación de una frase, y que afectan a nombres, adjetivos, verbos, preposiciones y adverbios.

Por lo que respecta a la consideración teórica de estos adverbios, es escasa la disonancia existente entre las teorías gramaticales españolas y las portuguesas, en las que se consideran adverbios interrogativos (con eventuales funciones exclamativas) las palabras que se utilizan en las oraciones interrogativas, bien directas, bien indirectas, y que clasifica del siguiente modo: (1) advérbios de causa, (2) de lugar, (3) de modo y (4) de tempo:

\footnotetext{
14 Alonso Cortés 1999.
} 


\begin{tabular}{|l|l|l|}
\hline 1. A. de causa: & por que & $\begin{array}{l}\text { Por que você não quer me entender? } \\
\text { Dize-me por que você não quer me entender. }\end{array}$ \\
\hline 2. A. de lugar: & onde & $\begin{array}{l}\text { Onde está o meu pai? } \\
\text { Ignoro onde está o meu pai }\end{array}$ \\
\hline 3. A. de modo: & como & $\begin{array}{l}\text { Como vamos sair deste problema? } \\
\text { Não sei como vamos sair deste problema }\end{array}$ \\
\hline 4. A. de tempo: & quando & $\begin{array}{l}\text { Quando terei descanso? } \\
\text { Quero saber quando terei descanso? }\end{array}$ \\
\hline
\end{tabular}

Llama la atención la consideración de por que como adverbio interrogativo, si bien no debe negarse cierta lógica interna de analogía con las demás partículas del cuadro: si onde interroga sobre el lugar, por que lo hace sobre la causa, como otra circunstancia más de la acción del verbo.

Pero se trata, como veíamos anteriormente, de un problema teórico que quizá no llegue a afectar al habla cotidiana del aprendiz.

\subsection{Errores generalizados}

Ocupa un lugar destacado en la cuestión de estos adverbios un tipo de error que consiste en la utilización por parte del aprendiz de algunas de estas palabras interrogativo-exclamativas de un modo diferente a como se hace en español, problema que se vincula al fenómeno análogo aplicable a los pronombres interrogativos-exclamativos.

Analizaremos, los usos erróneos de estos elementos que más dificultades morfosintácticas plantean al estudiante.

4.1.1. La partícula qué capitaliza un fenómeno ciertamente extendido entre los estudiantes lusófonos de español, que muestra nuevamente una estrategia de aproximación a partir de su LM. Lo constituye el caso de secuencias en las que intervienen adjetivos o adverbios, y que en español responden a una estructura del tipo

(24) ¡Qué tarde has venido!

Aunque la norma es quizá más estricta en el español peninsular, es normativo que en estos casos se invierta el orden normal entre el sujeto y el verbo: 
(25) a. ¿Qué pánfilo eres tú también! (*QQué pánfilo tú eres también!).

b. QQué bien cantaba mi padre! (*QQué bien mi padre cantaba!).

c. ¿Qué horroroso le queda el bigote! (*QQué horroroso el bigote le queda!).

Por su parte, el portugués permite más posibilidades, que oscilan entre formas aparentemente informativas hasta las claramente exclamativas y enfáticas:

(26) Veio tarde; Veio muito tarde; Que tarde veio; Que tarde que você veio; Nossa, mas como você veio / chegou tarde!

Por lo general, y como afirman Valmaseda y Aparício 1998, es de uso habitual en portugués el uso de como frente a que:

O português costuma preferir como, e o espanhol qué em expressões ponderativas ou exclamativas:

Como é grande esta cidade! ¡Qué grande es esta ciudad!

Sirva esta muestra, tomada de unos versos de Alphonsus de Guimaraens ${ }^{15}$, como ejemplo de ello:

Como são cheirosas as primeiras rosas

E os primeiros beijos como têm perfume!

Un ejercicio rápido de traducción al español podría pasar desde el arcaico/poético

¡Cuán olorosas son...

...cuánto perfume tienen / cuán perfumados están!

hasta el estándar

¿Qué olorosas son...

...qué perfume tienen!

A la luz de estas diferencias morfofuncionales, no resulta extraño encontrar secuencias erróneas que ponen de manifiesto la idiosincrasia de la L1 o de la interlengua a la L2, con una frecuencia de uso que afecta tanto a las interrogativas indirectas como a las exclamativas, especialmente en la estructura básica del tipo

$$
\begin{gathered}
(\text { SUJETO } 1)+(\text { VERBO } 1)+\text { COMO }+ \text { VERBO } 2(\text { SEMI }) \text { COPULATIVO } \\
+ \text { ATRIBUTO }+ \text { SUJETO } 2,
\end{gathered}
$$

con posibles alteraciones de orden entre estos dos elementos finales:

\footnotetext{
15 Obra completa, Río de Janeiro, 1960, Livraria José Olímpio Editora.
} 
(27) *soy testigo de cómo eres dedicado y responsable; *Tú sabes cómo tengo ganas de estar otra vez ahi; * cómo me puse contento; * para que veas cómo son grandes las distancias; *imaginar cómo me quede contenta; * cómo me quedé feliz; * cómo será buena tu venida; * ¡cómo es bueno saber que lo has conseguido!; * no te imaginas cómo es malo quedarse lejos; *un ejemplo de cómo es avanzada; *no sabes cómo me quedé feliz en saber; * cómo este hombre es viejo y feo; * no sabes cómo me quedé contento en haber sabido; *quiero mostrarte cómo mi país es hermoso; etc.

La afirmación de estar ante un caso palmario de interferencia la ratifica el hecho de que la sintaxis portuguesa en este tipo de estructuras vuelve a marcar distancias con la española, al tiempo que parece alinearse con las de otros idiomas con los que en teoría guardaría una distancia interlingüística mayor.

Como hemos visto con anterioridad, podríamos estar ante un caso de lo que podemos llamar el «efecto intercesor» de otra lengua, quizá más visible en aprendices de español de otras LM más alejadas, pero no por ello descartable.

Es probable que en este caso el «efecto intercesor» del inglés -el efecto intercesor por antonomasia en la enseñanza secundaria de una inmensa mayoría de estudiantes- no sea la única causa de los errores, pero sí puede ejercer una influencia de apoyo o confirmación.

Como es sabido, en esta lengua la expresión con how -muy usado para introducir exclamaciones, acompañado de adjetivos, adverbios, y otras combinaciones- exige una estructura muy estable, dado que el adjetivo o el adverbio debe aparecer inmediatamente detrás de how:

(28) a. How cold it is! ( $\rightarrow$ iQué frío hace!).

b. How beautifully you sing! ( $\rightarrow$ iQué bien cantas!).

c. How you've grown! $(\rightarrow$ ¡Cómo has crecido!).

Esta fuerte ordenación sintáctica parece estar detrás de producciones como éstas, tomadas de algunos corpus auxiliares de candidatos de Chicago:

(29) a. *cómo es tan incomodo.

b. *No importando [...] qué tan cansados; etc.

A modo de ejercicio contrastivo múltiple, véanse las siguientes oraciones comparadas, que muestran un caso más de alejamiento del español de las lenguas con las que comparte espacio y tiempo, distanciamiento que inevitablemente se revela en la clase de ELE como un obstáculo más en el PEA.

Si comparamos estas oraciones interrogativas/exclamativas en español, inglés, francés e italiano, las conclusiones corroboran las ideas expuestas: 


\begin{tabular}{|c|c|}
\hline ESPAÑOL & ITALIANO \\
\hline 1. ¿Qué tarde vienes! & 1. Come ti sei ritardatario! ${ }^{16}$ \\
\hline 2. No sabes lo hondo que es este río. & $\begin{array}{l}\text { 2. Non sai come é profondo questo } \\
\text { fiume }{ }^{17}\end{array}$ \\
\hline $\begin{array}{l}\text { 3. Ella me preguntó cuántos años } \\
\text { tenía. }\end{array}$ & 3. (Lei) mi chiese quanti anni avevo. \\
\hline FRANCÉS & INGLÉS \\
\hline 1. Comme tu arrives en retard! ${ }^{18}$ & 1. How late you are! \\
\hline $\begin{array}{l}\text { 2. Tu ne sais pas comme cette rivière } \\
\text { est profonde }{ }^{19}\end{array}$ & $\begin{array}{l}\text { 2. You don't know how deep this } \\
\text { river is. }\end{array}$ \\
\hline 3. Elle m'a demandé quel âge j'avais. & 3. She asked me how old I was. \\
\hline
\end{tabular}

La sola existencia de la posibilidad de decir en portugués Nossa, mas como você veio/chegou tarde! '¡Madre mía/Dios mío, pero qué tarde has venido!' es suficiente motivo para considerar el aislamiento del español en este aspecto, aparentemente secundario de la sintaxis.

Los errores en las formulaciones exclamativas se repiten con una frecuencia tal que nos lleva a pensar en la fosilización y extensión de un problema de fuerte interferencia de la LM de intensidad similar a la del calco.

El estudiante se encuentra con problemas de avance para superar esta fase, dado que supone una transformación brusca de su sintaxis, hasta el punto de que podría hablarse de un tipo de traducción.

Así, hará falta una exposición más intensa y de calidad a la L2 para que el estudiante llegue a producir secuencias como éstas ${ }^{20}$ :

(30) a. Soy testigo de lo dedicado y responsable que eres / Soy testigo de cómo eres de dedicado y responsable;

\footnotetext{
${ }^{16} \mathrm{O}$ diferentes combinaciones del tipo Come ti sei in ritardo! o Quanto arrivi tardi!

17 Amén de construcciones como Non sai / immagini quanto é profondo questo fiume.

18 Además de otras posibilidades como Qu'est-ce que tu viens tard! o Tu viens (trés) tard!

19 También formulables como Tu ne sais pas à quel point cette rivière est profonde o Tu ne connais pas la profondeur de cette rivière.

${ }^{20}$ En estos casos es donde, como afirma G. Torrego 2000, «el relativo que a veces tiene como antecedente un adjetivo o un adverbio», por lo que «sería más lógico hablar respectivamente de proadjetivo o proadverbio».
} 
b. Tú sabes las ganas que tengo de estar otra vez ahí / Tú sabes qué ganas tengo de estar otra vez ahí;

c. qué contento me puse / cómo me puse de contento;

d. para que veas lo grandes que son las distancias / para que veas cómo son de grandes las distancias;

e. imaginar lo contenta que me quede / imaginar cómo me quedé de contenta;

f. lo buena que será tu venida / qué buena será tu venida; etc.

Sólo mediante un proceso de sistematización muy tenaz de este uso podría eliminarse la presencia de este error fosilizable en los adverbios. La mayoría de ellos siguen estando muy presentes en las producciones orales y escritas de hablantes de español de lengua materna portuguesa, incluso de niveles considerados próximos al bilingüismo, concepto, por otra parte sujeto a discusión y de características tan difusas (Naiman y otros 1978 o Reiss 1985).

4.1.2. Asimismo, la partícula portuguesa quanto es otro punto conflictivo, pues parece causar una serie de errores, no tanto por la eventual ausencia de su equivalente en español, como por su valor arcaizante. Aunque no suele perturbar a la comunicación, sí afecta a su calidad.

Quanto convive con la forma quão, plenamente vigente en portugués, y puede aparecer ante adjetivo/participio/adverbio, situación ya perdida en español y sustituida por un obsoleto cuán, pero sobre todo por qué.

Así, son correctas en portugués secuencias del tipo:

(31) a. Quão estúpido fui!

b. Quão duro travalho!

Tanto la existencia de esta estructura como la neutralización de quão y quanto en el español cuanto (incluso «quanto») parecen revelarse como las verdaderas causas de la producción de oraciones como las que siguen:

(32) *Yo sé cuanto mis oportunidades son importantes; *no puede imaginar lo cuanto estoy contenta; *no sabes lo cuanto me quedé sorpresa; *no sabes lo cuanto me puse sorpresa; etc.

Se trata también de un error muy susceptible de fosilizarse, ya que sólo en estadios de interlengua más avanzados es posible detectar el cambio a formas aceptables en español estándar: bien mediante la desaparición del cuantificador a favor de una secuencia formada por $l o+$ adjetivo/participio/adverbio + que, bien mediante una mera sustitución por un cuasi omnipresente qué, con cierta transposición de las partes implicadas: 
(33) a. Yo sé lo importantes que son mis oportunidades / Yo sé qué importantes son mis oportunidades;

b. no puede imaginar lo contenta que estoy / no puede imaginar qué contenta estoy;

c. no sabes lo sorprendida que me quedé /no sabes qué sorprendida me quedé; etc.

De forma similar a lo indicado para el caso anterior, es precisa una sistematización constante para evitar y corregir este error fosilizable, que mantiene una fuerte tendencia a permanecer en las producciones de hablantes lusófonos, incluso con aceptables niveles de dominio del idioma.

\section{Conclusiones}

A modo de suma de conclusiones, y a la vista de los resultados empíricos del análisis de las producciones, parece confirmarse el hecho de que, igual que sucede con otras partes de la oración, también en los adverbios, la proximidad de ambas lenguas, lejos de facilitar un conocimiento real de la lengua que se aprende, constituye un obstáculo en sí misma.

El portugués y el español, por decirlo de alguna forma, se parecen demasiado para facilitar el aprendizaje de una de ellas desde la otra, por lo que estamos con Lee 1968 cuando asegura -oponiéndose radicalmente a Lado 1957 [1991]- que son precisamente las grandes diferencias las que podrían ayudar a eliminar cualquier rastro de la L1 y afirma:

Donde las similitudes son grandes, la confusión es casi inevitable.

La idea sostenida por otros muchos autores, es así sintetizada por Fernández 1997:

la mayor proximidad es factor de facilitación, aunque es justamente también en las estructuras más próximas donde es más viable la interferencia.

Conscientes de este hecho, estimamos que, pese a la rentabilidad y comodidad que en determinados momentos puede proporcionar la similitud de dos lenguas, podría asegurarse que a menor distancia interlingüística, mayor cantidad de determinados errores, y, lo que es más grave, mayor capacidad de fosilización y mayor resistencia a la eliminación de tales desviaciones, especialmente las referidas a partes de la oración como los determinantes y similares.

Se impone, por tanto, tratar de iniciar el estudio de cualquiera de estas dos lenguas desde su hermana situándose en estas dos actitudes: 
1. Debe evitarse en todo momento iniciar la enseñanza y el aprendizaje in medias res, por tener la impresión de que no es necesario comenzar por el principio, o que debe hacerse tabula rasa del supuesto conocimiento previo que el estudiante crea tener de la lengua que empieza a estudiar.

2. Pese a que la capacidad de entendernos sea un elemento favorecedor y socialmente atractivo, nunca debe prevalecer la comodidad de conformarse con comunicarnos sobre la necesidad de aprender correctamente la L2 desde el principio.

Esta segunda actitud encierra el eterno debate sobre corrección y comunicatividad, aunque no éste el momento ni el espacio para ello.

\section{REFERENCIAS BIBLIOGRÁFICAS}

Alonso Cortés, A. (1999): «Las construcciones exclamativas. La interjección y las expresiones vocativas», en Bosque, I. y Demonte, V. (eds.) Gramática descriptiva de la lengua español, 3 vols., Madrid, Real Academia de la Lengua / Espasa.

Andersen, R. W. (1983): «Transfer to somewhere», en Gass, S. y Selinker, L. pp. $177-201$.

Bosque, I. y Demonte, V. (eds.) (1999): Gramática descriptiva de la lengua español, 3 vols., Madrid, Real Academia de la Lengua, Espasa.

Buarque de Holanda Ferreira, A. (1999): Novo Aurélio Século XXI: O Dicionário da Lingua Portuguesa, Rio de Janeiro, Nova Fronteira.

Cipro Neto, P. e Infante, U. (1999): Gramática da língua portuguesa, São Paulo, Editora Scipione.

Cunha, C. y Cintra, L. (1995): Nova Gramática do Português Contemporâneo, $10^{\underline{a}}$ ed., Lisboa, Ed. J. Sá da Costa.

DurÃo, A. B. de A. B. (1999): Análisis de errores e interlengua de brasileños aprendices de español y de españoles aprendices de portugués, Londrina, UEL.

—, (2007): La interlengua, Madrid, Arco/Libros.

Gass, S. y Selinker, L. (eds.) (1983): Language Transfer in Language Learning, Newbury House, Rowley, Mass.

Gómez Torrego, L. (2000): Ejercicios de gramática normativa (I y II), 2ª ed., Cuadernos de lengua española, Madrid, Arco/Libros.

Instituto Antônio HouAiss (2001): Dicionário Houaiss da Lingua Portuguesa, Rio de Janeiro, Ed. Objetiva.

LADO, R. (1957): Linguistics across Cultures: Applied Linguistic for Language Teachers, Ann Arbor, University of Michigan Press. (trad. esp.: Lingüistica contrastiva, lenguas y culturas, Madrid, Ediciones Alcalá, 1991).

LEE, W. (1968): «Thoughts in Contrastive Linguistics in the Context of Language Teaching», en Alatis (ed.). "Report on the XIXth Annual Roundtable Meeting on Linguistics and Language Studies», Contrastive Linguistics and its Pedagogical Implications, Washington, Georgetown University, pp. 185-194. 
MARTínez VÁzQuez, M. (ed.) (1996): Gramática contrastiva inglés-español, Huelva, Servicio de Publicaciones.

NAiman, N.; Fröhlich, M.; STERn, H. y Todesco, A. (1978): «The Good Language Learner», Research in Education Series 7, The Ontario Institute for Studies in Education, Toronto, Reprinted Multilingual Matters, 1995.

Norrish, J. (1983): Language Learners and Their Errors, Londres, MacMillan Publishers. (Col. Essential Language Teaching Series).

Real Academia Española (1992): Diccionario de la lengua española, Madrid, Espasa.

ReISs, M. (1985): «The good language learner: another look», Canadian Modern Language Review 41, pp. 511-523.

SANTOS Gargallo, I. (1993): Análisis contrastivo, análisis de errores e interlengua en el marco de la Lingüistica Contrastiva, Madrid, Síntesis.

Torijano Pérez, J. A. (2003): Análisis teórico-práctico de los errores gramaticales en el aprendizaje del español, L-2: expresión escrita, Salamanca, Ediciones Universidad de Salamanca.

—, (2004): Errores de aprendizaje, aprendizaje de los errores, Madrid, Arco/Libros.

—, (2006a): «Conciencia de error en los buenos aprendices residentes en países hispanohablantes», en Bustos Gisbert, J. M. y Sánchez Iglesias, J. (coords.), La fosilización en la adquisición de segundas lenguas: el buen aprendiz, Salamanca, Hispano Lusa de Ediciones.

—, (2006b): «Lo que nos enseñan los errores», Revista Signum: Estudos da Linguagem, Londrina (Paraná, Brasil), Universidade Estadual de Londrina.

Valmaseda Regueiro, M. Á. y Aparício Burgos, M. (1998): Michaelis S.O.S. Espanhol: guia prático de gramática, São Paulo, Melhoramentos.

VÁzQUEZ, G. (1986): «Hacia una valoración positiva del concepto de error», en Actas de las I Jornadas Internacionales de Didáctica del Español, Lengua Extranje$r a$, Las Navas del Marqués, pp. 25-28.

—, (1991): Análisis de errores y aprendizaje de español / lengua extranjera. Análisis, explicación y terapia de errores transitorios y fosilizables en el proceso de aprendizaje del español como lengua extranjera en cursos universitarios para hablantes nativos de alemán, Frankfurt am Main, Peter Lang.

—, (1999): ¿Errores? ¡Sin falta!, Madrid, Edelsa.

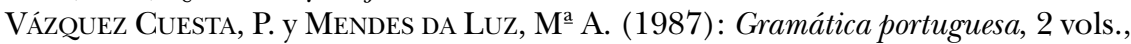
Madrid, Gredos.

WeinRich, U. (1974): Languages in Contact, La Haya, Mouton. 